\title{
GEOID MODELLING USING INTEGRATION AND FFT ASSOCIATED WITH DIFFERENT GRAVIMETRIC REDUCTION METHODS
}

\author{
Éder Teixeira Marques ${ }^{1}$, William Rodrigo Dal Poz ${ }^{1}$ and Gabriel do Nascimento Guimarães ${ }^{2}$
}

\begin{abstract}
A vertical reference system is characterized by a vertical datum and a set of scientific altitudes. In the case of orthometric altitudes, the geoid is used as a reference surface, equipotential surface of the gravity field of the Earth that better fits, in the sense of the Least Square Method, to the mean sea level. This study aimed to determine the geoid by applying two processes for calculation of residual ondulation, the integration and the Fast Fourier Transform. These techniques were applied to the values of the residual anomalies obtained from different methods of gravimetric reduction: the Helmert's Second Method of Condensation, Bouguer and Rudzki. Two test areas were used. For area 1, the best gravimetric geoid was obtained by applying 1D planar FFT with the Helmert's Second Method of Condensation. For area 2 , the best gravimetric geoid was obtained through the application of integration and the Rudzki's reduction. It can be concluded that the physical characteristics of both areas are relevant in the determination of the geoid and that additional procedures must be applied to improve the geoid determination, mainly, in area 2 whose physical characteristics are more heterogeneous than in area 1.
\end{abstract}

Keywords: geoid, GeoFis 1.0, gravimetric reduction, FFT, Stokes Integral.

RESUMO. Um sistema vertical de referência é caracterizado por um datum vertical e pelo conjunto de altitudes científicas. No caso das altitudes científicas adotadas serem as ortométricas utiliza-se como superfície de referência o geoide, superfície equipotencial do campo da gravidade da Terra que melhor se ajusta, no sentido do método dos mínimos quadrados, ao nível médio do mar. 0 objetivo desse trabalho foi determinar o geoide aplicando dois processos de cálculo da ondulação residual, a integração e a Transformada Rápida de Fourier. Essas técnicas foram empregadas aos valores de anomalias residuais obtidas a partir de diferentes métodos de redução gravimétrica: Segundo Método de Condensação de Helmert, Bouguer e Rudzki. Foram utilizadas duas áreas de teste. Verificou-se que para a área 10 melhor geoide gravimétrico foi obtido pela aplicação da FFT planar 1D juntamente com o Segundo Método de Condensação de Helmert. Para a área 20 melhor geoide gravimétrico foi obtido pela aplicação da integração e da redução de Rudzki. Conclui-se que as características físicas das duas áreas são relevantes na determinação do geoide e que procedimentos complementares devem ser aplicados para melhorar a determinação do geoide, principalmente, na área 2 cujas características físicas são mais heterogêneas do que da área 1.

Palavras-chave: geoide, GeoFis 1.0, redução gravimétrica, FFT, Integral de Stokes.

\footnotetext{
${ }^{1}$ Universidade Federal de Viçosa, Departamento de Engenharia Civil, Setor de Engenharia de Agrimensura e Cartográfica, Av. Peter Henry Rolfs, s/n, Campus Universitário, 36570-000 Viçosa, MG, Brazil - E-mails: eder@ufv.br; william.dalpoz@ufv.br

2 Universidade Federal de Uberlândia, Campus Monte Carmelo, Rodovia LMG 746, Km 1, Bairro Araras, 38500-000 Monte Carmelo, MG, Brazil

- E-mail: gabrielguimaraes33@gmail.com
} 


\section{INTRODUCTION}

Global positioning systems (GLONASS, GALLILEO, GPS and Beidou) produced a large impact on the Geodesic Sciences. They enabled the determination of the position of any user, with a specific receiver, rapidly and accurately. The altitudes obtained by the GNSS (Global Navigation Satellite System) are referenced to the ellipsoid adopted by the system, meaning that, they are taken along the normal that is perpendicular to the surface of the mathematical model. However, the altitudes used in the day-to-day engineering are those taken along the plumb line, that is, they are perpendicular to the equipotential surface of the gravity field and therefore are defined as altitudes with physical meaning, unlike the altitudes perpendicular to the ellipsoid whose meaning is purely geometric.

In order to determine the altitudes with physical significance, one can use the geometric leveling which, depending on the horizontal leveled distance and the relief undulationg, must be associated with the gravity measures (Talvik, 2012) and also the geoid undulation can be used $(N)$, distance between the ellipsoid and the geoid along the normal, along with geometric altitude measurements $(h)$, as shown in Figure 1. This figure illustrates the geometric altitude, distance between the ellipsoid and the real surface measured along the normal direction $(n)$, the orthometric height $(H)$, distance between the geoid and the real surface measured along the vertical direction $(v)$ and the geoid undulation, $N$ distance along the normal between the ellipsoid and the geoid.

Mathematically, $H$ can be obtained by the mathematical relation given by Eq. (1).

$$
H \equiv h-N
$$

where:

$H=$ orthometric altitude

$h=$ geometric altitude, and

$N=$ geoid undulation.

From Figure 1, it can be verified that, from the values of $N$ and $h$ are derived the altitudes with physical significance of interest in the practical engineering activities.

According to Listing (1873), the geoid is an equipotential surface of the gravity field of the Earth that better fits, in the sense of the least squares method, to the mean sea level. In geodesy, this surface is treated as reference to the measures of orthometric altitudes. When assuming the geoid as a vertical reference surface, such measures start being observed along the vertical of the location, such as the case of the measures of height in the Local Astronomical System (Jekeli, 2006).
After defining the surface to be used as the level reference, of geopotential $W_{0}$, it can be performed the vertical system of reference using, geometric leveling associated with gravimetry or the geoid undulation associated with geometric altitudes. In this case, stands out the utilization of the Geopotential Global Models (GGMs) from the spatial missions of low-orbit artificial satellites Gravity Recovery and Climate Experiment (GRACE), CHAlleging Minisatellite Payload (CHAMP) and Gravity field and steady-state Ocean Circulation Explorer (GOCE).

Another parameter of great importance in modelling the external gravity field are the Elevation Digital Models (EDMs). The accuracy of these models has improved considerably in the last few years. It is the case of the Shuttle Radar Topography Mission (SRTM), which according to Kiamehr \& Sjöberg (2005), reaches horizontal accuracy of 20 meters and vertical accuracy of 16 meters.

The regional geoid can be obtained by the application of the Remove-Restore (RR) technique. In this procedure, both topography and the low-degree signals of the global geopotential models must be removed before the calculation and restored after the application of the Stokes Integral (Yildiz et al., 2012).

In the application of RR, the geoid model is determined from the separation of the components of the gravity field into different wavelengths. The components of medium and long wave of the spectral decomposition of the gravity field are obtained from the geopotential models, coefficients from the serial expansion of harmonic spherical functions, derived from variations in the orbit of the satellites that are sensitive to alterations in the Earth's gravitational field. The anomalies, obtained from the acceleration of gravity measured at the Earth's surface, used by Stokes (1849) for the solution of the Geodetic Boundary Value Problem (GBVP), constitute the components of medium wavelength. To improve the solution, it is necessary to use high frequency components, which can be done from the Digital Terrain Models (DTMs).

This work aimed to check for significant difference in the determination of the geoid for areas with different physical characteristics, geology and relief, when different gravimetric reduction methods are applied, according to the Helmert's Second Method of Condensation, Bouguer and Rudzki. In addition, the Stokes Integral will be evaluated using Fast Fourier Transform and integration.

\section{STUDY AREA}

Both study areas are illustrated in Figures 2 and 3. The region, named area 1, is located on the west of the state of São Paulo and the north of Paraná and the other region, area 2, encompasses 


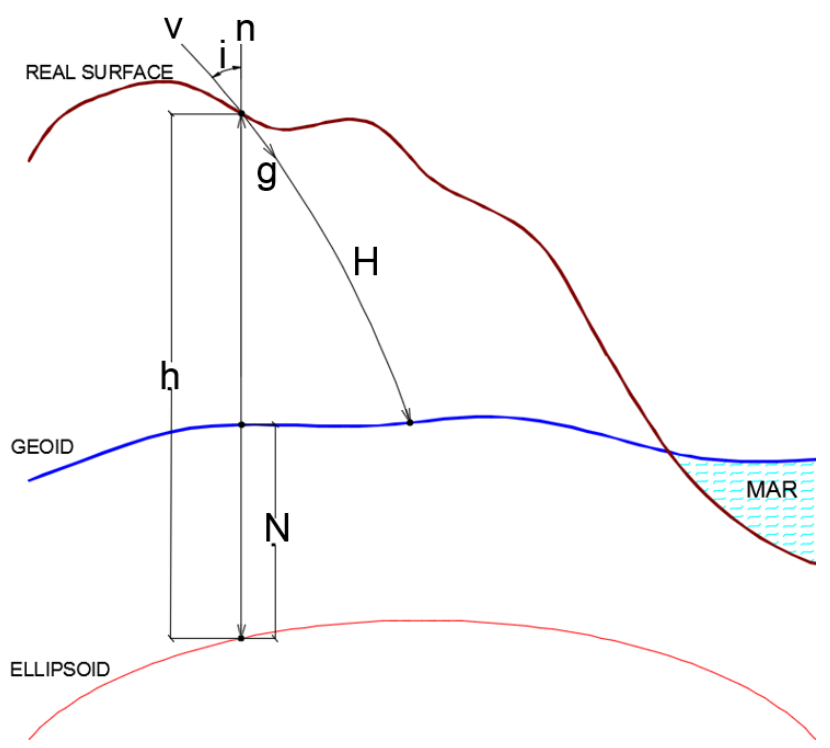

Figure 1 - Ellipsoid, geoid and real surface.

part of the south of Minas Gerais, north of São Paulo and south of the state of Rio de Janeiro. The area 1 is situated between the meridians $-52^{\circ} 43^{\prime} 29^{\prime \prime}$ and $-47^{\circ} 07^{\prime} 26^{\prime \prime}$ and between the parallels $-25^{\circ} 31^{\prime} 54^{\prime \prime}$ and $-19^{\circ} 54^{\prime} 32^{\prime \prime}$, as shown in Figure 2.
The area 2 (Fig. 3), situated in the south of Minas Gerais is located between the meridians $-48^{\circ} 40^{\prime} 05^{\prime \prime}$ and $-42^{\circ} 40^{\prime} 05^{\prime \prime}$ and between the parallels $-24^{\circ} 27^{\prime} 02^{\prime \prime}$ and $-18^{\circ} 51^{\prime} 02^{\prime \prime}$. The parameters used to select the study areas were: the amount of available

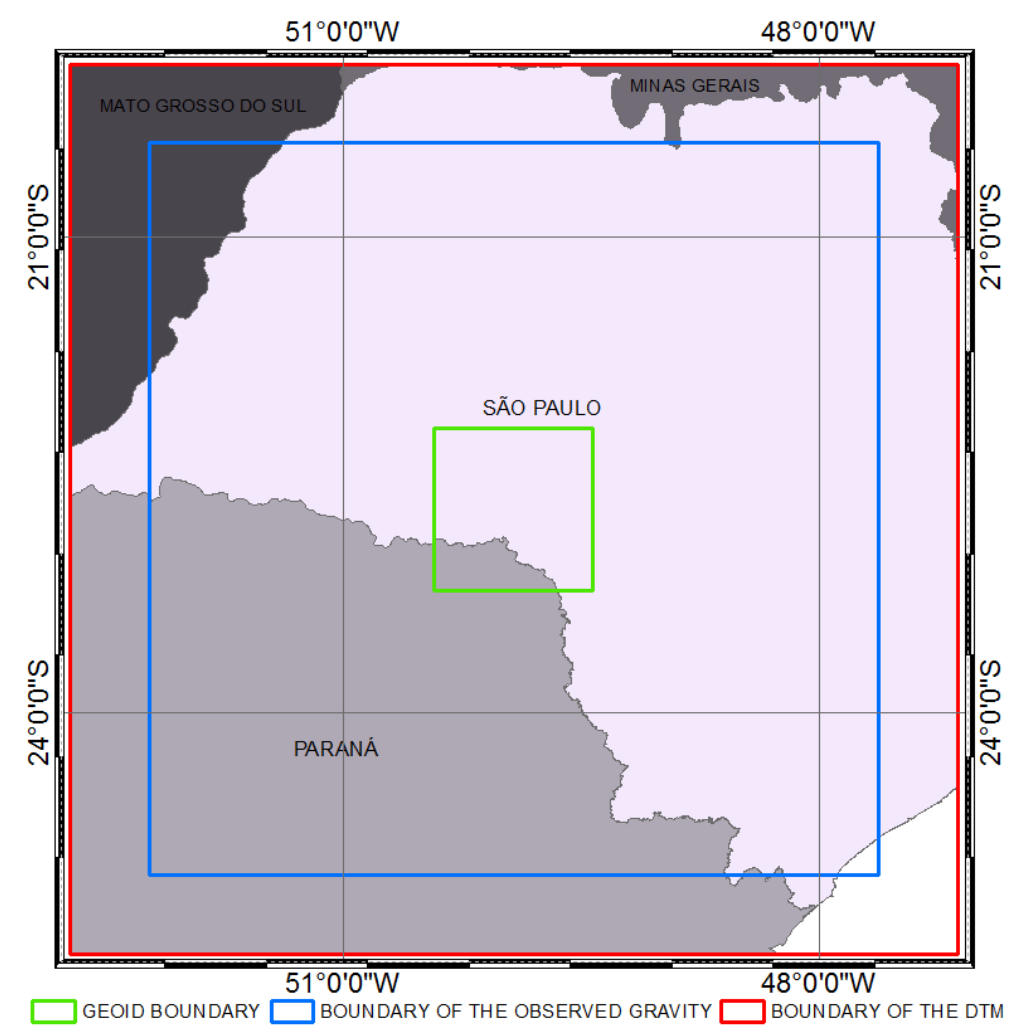

Figure 2 - Study area, limits of DTM, gravity anomalies and geoid area. 


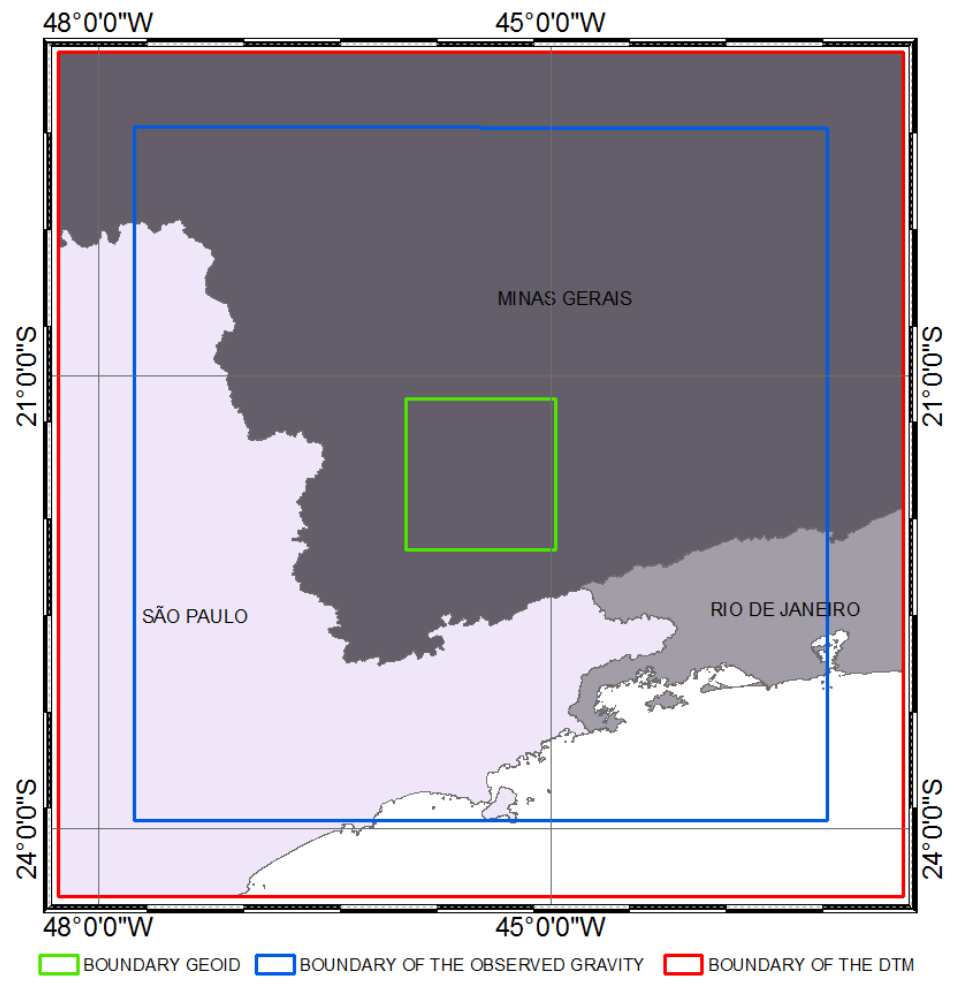

Figure 3 - Study area, limits of MDT, gravity anomalies and geoid area.

gravimetric information, the shape of the relief and the geology of the region. The geoid, regional/local, to be determined will have as limit the most internal polygon of $1^{\circ} \times 1^{\circ}$, shown in (Figs. 2 and 3).

In area 1 , there is predominance of sedimentary rocks. In this area, there are basically two large groups, the Bauru Group with predominance of siltstones, sandstones and sandy argillite, and the Caiuá Group, also with predominance of sandstone. In area 2, located predominantly in the south of Minas Gerais, there is the predominance of metamorphic rocks. In this area, there are two large groups, Varginha-Gauxupé and Andrelândia. In the first, there are amphibole, hornblende and Ca-plagioclase while in the other group, there are gneisses and schists. To the north of the MG area, it is also possible to observe the presence of igneous rocks of the Lavras group with the presence of granites, migmatites and granitoids.

\section{MATERIAL AND METHODS}

Most of the boundary value problems are solved in terms of the integrals, Stokes and Vening Meisnesz, over the entire contour surface. In Physical Geodesy, the application of these formulas has as presupposition the knowledge of physical quantities, disturbing potential, gravity anomalies, gravity disturbances, geoid undulation, deviation from the vertical and height anomaly, over the entire surface of the Earth. However, the gravimetric networks usually have few points, which causes the necessity of applying procedures of interpolation and extrapolation. Named as prediction, these methods do not return the real values, so they suggest the need to be able to estimate errors resulting from interpolation and extrapolation as well as the effects of these errors on the derived quantities and their effects due to the neglected distant regions.

The non-existence of functionals of the gravity field distributed continuously over the entire Earth's surface implies the necessity of using the remove-restore technique associated with the prediction procedure. Usually, the prediction is made by applying the Least Squares Colocation Method. The main problem of this approximation is to perform the correct modeling of the covariance function of observations, mainly when combined with different functionals of the disturbing potential. It is suggested, as an alternative, to apply Krigagem as a prediction method.

\section{Material}

The functionals of the gravity field used herein were provided by the institutions: Instituto Brasileiro de Geografia e Estatística (IBGE), Agência Nacional do Petróleo, Gás Natural e Biocom- 
bustíveis (ANP) and Technical University of Denmark (DTU). In addition to these data, it was used elevation digital models and the set of coefficients of the EIGEN-6C4 Geopotential Model (Förste et al., 2014). In order to validate the gravimetric geoid, in January 2017 a campaign was conducted to obtain geometric geoid data using GNSS on stations of the Rede Altimétrica Fundamental Brasileira, RAFB, by visiting 28 stations for area 1 and 29 for area 2. In this study, we also used the softwares: GeoFis 1.0 (Marques \& Freitas, 2017), FFTGEOID 1D-FFT and FFT planar (Sideris \& Li, 1993) and ArcGIS 10.5.

\section{Methodology}

The correct utilization of gravimetric data is associated with homogenization. Such objective is achieved by checking if the data are referenced to the same ellipsoid and gravimetric datum, removing repeated data and eliminating gross errors in the altitudes. According to Gemael \& Rosier (1991), Rede Nacional de Estações Gravimétricas Absoluta (RENEGA) has seven absolute stations, Brasília-DF, Curitiba-PR, Santa Maria-RS, Teresina$\mathrm{PI}$, Valinhos-SP, Vassouras-RJ and Viçosa-MG, all of those consistent with the International Gravity Standardization Net 1971 (IGSN-71), being therefore, homogeneous in terms of the gravimetric datum. As for the ellipsoid, according to IBGE, all the coordinates of the gravimetric stations are referenced to the Geodetic Reference System 1980 (GRS80).

In the homogenization process, it was checked the existence of data without orthometric altitude and duplicated. The observations that did not have orthometric altitudes were eliminated and for analysis of the repeated data, it was applied the methodology of Sevilla et al. (1997), i.e., stations that are apart from each other, along the parallels or the meridians, up to $0.0005^{\circ}$, approximately 55 meters, were considered duplicates.

From the total of 10375 gravimetric observations for area 1 , 27 were without associated orthometric altitude. As to area 2, from the total of 9520 observations of Earth's gravity, 47 were without observations of orthometric altitude.

For determination of duplicate points, it was used a program of Geographic Information System (SIG). In this case, there were detected 1382 points with a distance from each other of up to 55 meters for the area 1 and 310 points with a distance of up to 55 meters for the area 2.

To check for altimetric inconsistencies in the observations resulting from the applications performed, 8966 and 9163 observations for the areas 1 and 2, respectively, two analyses were applied, the graphic and the comparative.

In the graphic analysis, free air anomaly data were related to the orthometric altitudes with the purpose of detecting atypical points in the group of observations. Figure 4 shows the dispersal of the gravity anomaly in ascending order of altitude for area 1 . There are three groups of free air anomaly, one group with good cohesion and two other groups, circled, that are separated from the most cohesive group and need to be analyzed in more detail.

For area 2 (Fig. 5), it is perceptible an even larger dispersion of the data. The marked circles in this figure suggest the need for a detailed investigation of the values contained therein.

For an altimetric reference system, it is fundamental to have in the combination of GNSS, gravimetry and Global Geopotential Models (GGMs) consistency between the data. In the case of the remove-restore method, in which the MDEs and MDBs are essential, it is necessary to detect the one that is more consistent with the available altimetric data accessible in the gravimetric data basis. In this study, the MDEs SRTM 3 and ASTERGDEM V2 were evaluated. The MDE that resulted in the lower amount of data collected, according to the results presented in Tables 1 and 2, was SRTM and based on this criterion it was adopted.

Table 1 - Results of the difference between $h$ (MDT) - $H$ (orthometric) - area 1 .

\begin{tabular}{|c|c|c|}
\hline Statistics & SRTM $-H(\mathrm{~m})$ & ASTER $-H(\mathrm{~m})$ \\
\hline Minimum & 20.000 & 20.000 \\
Maximum & 518.370 & 514.370 \\
Mean & 51.380 & 47.493 \\
Standard Deviation & 52.828 & 49.033 \\
Variance & 2790.783 & 2404.262 \\
Greater than 20 meters & 709 & 844 \\
\hline
\end{tabular}

Table 2 - Results of the difference between $h(\mathrm{MDT})-H$ (orthometric) - area 2.

\begin{tabular}{|c|c|c|}
\hline Statistics & SRTM $-H(\mathrm{~m})$ & ASTER $-H(\mathrm{~m})$ \\
\hline Minimum & 20.000 & 20.000 \\
Maximum & 1206.290 & 1189.290 \\
Mean & 64.453 & 62.369 \\
Standard Deviation & 87.258 & 85.338 \\
Variance & 7614.043 & 7282.613 \\
Greater than 20 meters & 1347 & 1415 \\
\hline
\end{tabular}

As verified in Table 1, the discrepancies between the absolute values of altitude between the MDE, SRTM or ASTER, and the altitudes given by the BDG/BNDG for area 1 are consistent. Despite this condition, the analysis indicated 709 observations whose absolute altitude difference between the SRTM and the orthometric altitude exceeded 20 meters, totalizing $7.90 \%$ of the data and identified 844 observations whose absolute altitude difference between the ASTER and the orthometric altitude exceeded 20 meters, i.e., $9.41 \%$. 
Dispersion of free air anomaly according to orthometric altitude - Area 1

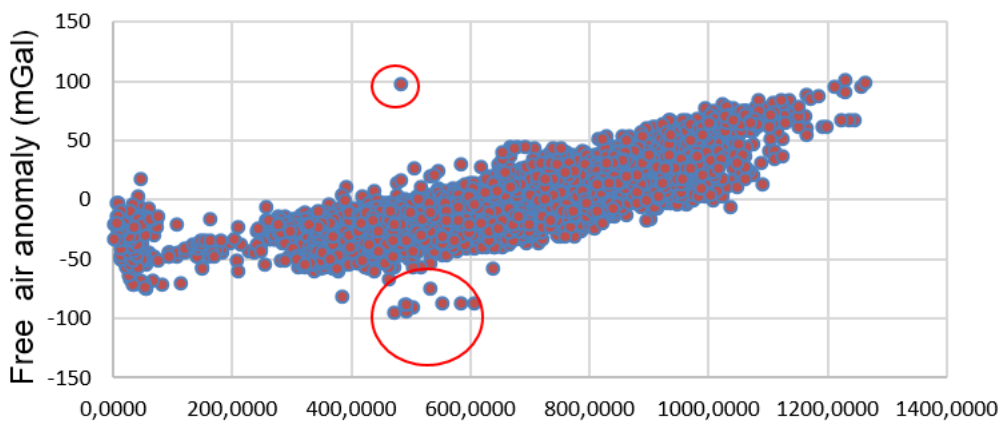

Orthometric altitude (meters)

Figure 4 - Dispersal of the free air anomaly in relation to the altitude of area 1.

Dispersion of free air anomaly according to orthometric altitude - Area 2

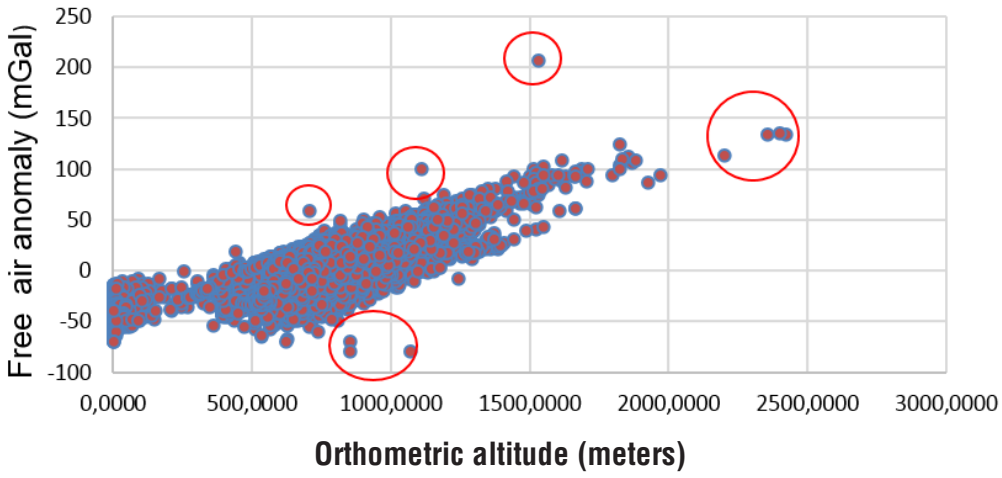

Figure $\mathbf{5}$ - Dispersal of the free air anomaly in relation to the altitude of area 2.

The analysis of the altimetric data for area 2, Table 2, identified 1347 observations whose absolute difference between the altitudes SRTM-orthometric exceeded 20 meters, i.e., a total of $14.70 \%$ of the previous validated observations. For this same area, the analysis identified, for the absolute difference of ASTERorthometric altitude, a total of 1415 stations, i.e., a total of $15.44 \%$ of observations above the established limit of 20 meters.

To verify if the observations resulting from the previous validations, 8257 and 7816 for the areas 1 and 2, respectively, meet the minimum quality requirements, it is necessary to apply mathematical methods that guarantee such condition. This study applied two mathematical models, the least square method and the geostatistics. In both cases, it is desired to predict values in positions where these values are already known, in case the differences between the predicted value and the known value are within a pre-established threshold, then the quality of these observations can be confirmed.

To apply this procedure it is necessary to apply the gravimet- ric reductions and to use the residual anomalies, that is, one must add the terrain correction to the free air anomalies and from this result subtract the gravity anomalies obtained according to a geopotential model.

\section{Steps of the Remove-Restore Technique}

In general, in order to apply the remove-restore technique, it is necessary to divide the signal of the gravity field into long, medium and short wavelengths. The values of the geoid undulation for long wavelengths are obtained by satellite observations, the spectrum of medium wavelength is obtained by measurements taken on the Earth's surface and the spectrum of short wavelengths is directly related to the terrain topography, MDE. The technical application consists in combining data from the geopotential models, obtained from satellite observations, with data measured on the Earth's surface and with the shape of the relief. The adopted methodology can be summarized as follows (Bajracharya, 2003): 
a) Measure the gravity value, $g_{o b s}$, and its geometric position, $\emptyset, \lambda$ and $h$ in the physical Earth's surface;

b) When using the solution of the boundary value problem, according to Stokes, the reductions must be applied to the observed gravity values and taken to the geoid. First, the atmospheric effects are removed, then the free air reduction is applied and subtracted the theoretical gravity, $y$, to obtain the free air anomaly, $\Delta g_{\text {Freeair. }}$. If it is desired to apply the Helmert's Second Condensation Method, one must obtain the Faye anomaly, $\Delta g_{\text {Faye }}$; for this, the terrain correction, $C T$, must be applied. The Faye anomaly is given by $\mathrm{Eq}$. (2):

$$
\Delta g_{\text {Faye }}=\Delta g_{\text {Freeair }}+C_{\text {atm }}+C T
$$

c) The next step is to eliminate, from the signal of the gravity field, the effects of the long wavelengths from the value of anomaly obtained in item b. From the coefficients of the geopotential models, truncated to a certain degree and order, the free air gravity anomaly, $\Delta g_{M G G}$, Eq. (3), is calculated. Where: $n$ is the degree of the model, $m$ is the order, $G M$ is the gravitational constant multiplied by the Earth mass, $a$ is the largest semi-axis of the adopted ellipsoidal model, $C_{n m}$ and $S_{n m}$ are the coefficients of the fully normalized geopotential model, $P n m$ are the normalized Legendre functions $r, \phi, \lambda$ are the spherical $c^{-}$ ordinates of the calculation points. In this case, the result is a regular grid with the same number of rows and columns of the grid obtained in the previous item containing $\Delta g_{M G G}$. The truncation must be performed in such a way that there is convergence to the calculated $N$ value. The gravity anomaly value for the coefficients of any global geopotential model is given by Eq. (3) (Souza et al., 2008):

$$
\begin{gathered}
\Delta g_{M G G}=\left(\frac{G M}{r \gamma}\right) \\
\times\left[\sum _ { n = 2 } ^ { \infty } \sum _ { m = 0 } ^ { n } ( n - 1 ) ( \frac { a } { r } ) ^ { n } \left(C_{n m} \cos m \lambda\right.\right. \\
\left.\left.+\bar{S}_{n m} \sin m \lambda\right) \bar{P}_{n m}(\cos \theta)\right]
\end{gathered}
$$

d) With the results of the Eqs. (2) and (3), the values of residual anomalies are determined, $\Delta g_{\text {res }}$

$$
\Delta g_{\text {res }}=\Delta g_{\text {Faye }}-\Delta g_{M G G}
$$

e) With values of the complete Bouguer correction $\left(C_{B}\right)$, the residual anomalies can be calculated, according to Eq. (5)

$$
\Delta g_{B}=\Delta g_{\text {Freeair }}+C_{a t m}-C_{B}-\Delta g_{M G G}
$$

f) In the case of the application of the complete Bouguer correction, due to the great indirect effect caused by the removal of masses, it is necessary to restore them. For that, the Eq. (6) is applied.

$$
\Delta g_{\text {res }}=\Delta g_{B}^{\text {grid }}+2 \pi G \rho H^{\text {grid }}
$$

g) Applying the Rudzki's correction to Eq. (7), the values of residual anomalies of Rudzki are determined.

$$
\Delta g_{\text {res }}=\Delta g_{\text {Freeair }}-C_{R}-\Delta g_{M G G}
$$

h) the values obtained by Eqs. (4), (6), and (7) are used as input to Stokes Integral, Eq. (8), Gemael (1999). Where: $N_{\text {res }}$ is the portion of the geoid undulation referred to the mean wavelengths in the gravity field, $S(\psi)$ is the kernel of the Stokes Integral and $d \sigma$ is the area element of a regularly spaced grid with data of the residual anomalies obtained by Eqs. (4), (6) and (7). This grid is determined using different interpolation methods, in this case, it should be prioritized more robust models that employ covariance functions, for example, least squares placement and geostatistics.

$$
N_{\text {res }}=\frac{R}{4 \pi \gamma} \iint_{\sigma} \Delta g_{\text {res }} S(\psi) d \sigma
$$

i) The Eq. (9) is used to determine the geoid undulation relating to the long wavelengths of the gravity field, $N_{M G G}$. Where: $N_{0}$ expresses the difference of mass and potential between the ellipsoid of reference and the ellipsoid used in the determination of coefficients and $C_{n m}$ is the difference between the fully normalized coefficients of the expansion in spherical harmonics of the geopotential and the spheropotential. According to Souza et al. (2008), it can be obtained by Eq. (9):

$$
\begin{gathered}
N_{M G G}=N_{0}+\frac{G M}{r \gamma} \sum_{n=2}^{360}\left(\frac{a}{n}\right)^{n} \sum_{m=0}^{n} \\
\times\left(\Delta \bar{C}_{n m} \cos m \lambda+\bar{S}_{n m} \sin m \lambda\right) \bar{P}_{n m}(\cos \theta)
\end{gathered}
$$

j) It must be considered the indirect effect, $N_{E I}$. This effect occurs by the alteration of the potential of gravity from the removal or dislocation of mass during the application of the gravimetric reductions. For the Helmert's Second Condensation Method, the solution proposed by 
Wichiencharoen (1982) for the indirect effect is given by the Eq. (10):

$$
\begin{aligned}
N_{E I}= & -\frac{\Delta g_{B} \cdot H_{p}}{\gamma_{P}}-\frac{G \rho}{6 \gamma_{P}} \iint_{\sigma} \frac{H^{3}-H_{P}^{3}}{d^{3}} d \sigma \\
& +\frac{3 G}{40 \gamma_{P}} \iint_{\sigma} \frac{H^{5}-H_{P}^{5}}{d^{5}} d \sigma
\end{aligned}
$$

where $\Delta g_{B}$ is the Bouguer anomaly, $H$ is the altitude of the points of terrain grid, $H_{p}$ is the altitude in the point of calculation, $\gamma_{P}$ is the theoretical gravity in the point of calculation, $\rho$ is the density of the crust and $d$ is the distance between the point of calculation and the integration point.

k) The restore step, consists in the sum of the values of undulation for the different wavelengths. Thus, the gravimetric geoid is obtained by Eq. (11):

$$
N=N_{\Delta M G G}+N_{\text {res }}+N_{E I}
$$

There are variations for the calculation of $N_{E I}$ that should be considered. Some reductions, in order to be applied, modify the topography and cause considerable indirect effects by moving the geoid away from the ellipsoid. It is the case of the Bouguer reduction, so it is not used to determine the geoid only for interpolation (Hofmann-Wellenhof \& Moritz, 2005). Nevertheless, certain reductions cause small indirect effect as is the case of the topo-isostatic reduction that remove the effects of masses considering some isostatic principle. In other cases, as in the Rudzki inversion, there is no change in the disturbing potential and therefore the indirect effect is assumed to be null.

The application of the free air reduction as suggested previously does not imply in the removal of masses only in the dislocation of the point of observation of gravity to the point of the mean sea level.

In general, the indirect effect is a relation between the variation of the anomalous potential before and after the removal of masses, $\Delta T=T-T_{D}$, and the theoretical gravity, $\gamma$. Sideris (1997) suggest the Eq. (12):

$$
N_{E I}=\frac{\Delta T}{\gamma}
$$

where $T$ refers to the disturbing potential due to topographic masses and $T_{D}$ is the potential after the application of each reduction method.

\section{RESULTS AND ANALYSIS}

Values of free air anomaly were calculated from gravity data and the orthometric altitude given by the IBGE and by the Banco
Nacional de Dados Gravimétricos (BNDG), of ANP. In turn, DTU data refer to the free air anomaly for the ocean area complementing the data furnished by Brazilian agencies. Figure 6 illustrates the distribution of the free air anomalies for the study areas.

As this anomaly is highly correlated to altimetry, the high frequency of the latter will reflect in the sinuosity of the free air model.

Comparing the graphs in Figure 6 , it is evident that the modeled of area 2 is much more wavy than the modeled of area 1.

In GeoFis 1.0 the terrain correction is determined by the method of prisms applied following the proposition of Ma \& Watts (1994). Figure 7 represents the frequency distribution for the correction of the terrain by the software GeoFis 1.0, for the areas 1 and 2, respectively. All the calculations utilized the density of $2.67 \mathrm{~g} / \mathrm{cm}$.

The results in Figure 7 shows that the highest frequency of values for the terrain correction occurs in the interval $0-2 \mathrm{mGal}$ for area 1 and $1-4 \mathrm{mGal}$ for area 2. The software GeoFis 1.0 uses the inclined surface of the terrain as being the top of the prism, so the result of calculating the terrain correction gives significant results of the influence of the relief variation. This is verified when comparing the areas in Figure 7.

The Faye anomaly for the Helmert's Second Condensation Method is the free air anomaly with terrain correction. The anomaly of Rudzki is the free air anomaly with the Rudzki's correction and Bouguer refers to the application of the complete Bouguer correction to free air anomalies. Tables 3 and 4 present the statistical summary of these three applications for the study areas.

Table 3 - Result of anomalies in mGal for area 1 from the application of the three reduction methods.

\begin{tabular}{|c|c|c|c|}
\hline Statistics & Helmert & Bouguer & Rudzki \\
\hline Minimum & -71.570 & -118.724 & -67.814 \\
Maximum & 102.392 & 13.538 & 87.710 \\
Mean & -11.656 & -75.633 & -12.696 \\
Std Deviation & 23.346 & 14.906 & 22.220 \\
\hline
\end{tabular}

Table 4 - Result of the anomalies in mGal for area 2 from the application of the three reduction methods.

\begin{tabular}{|c|c|c|c|}
\hline Statistics & Helmert & Bouguer & Rudzki \\
\hline Minimum & -79.278 & -200.111 & -88.621 \\
Maximum & 137.521 & -11.374 & 109.370 \\
Mean & 4.116 & -84.396 & 4.882 \\
Std Deviation & 25.455 & 18.372 & 23.381 \\
\hline
\end{tabular}

In Table 3, the means of the methods of Helmert and Rudzki were closer to each other than the one obtained with the reduc- 

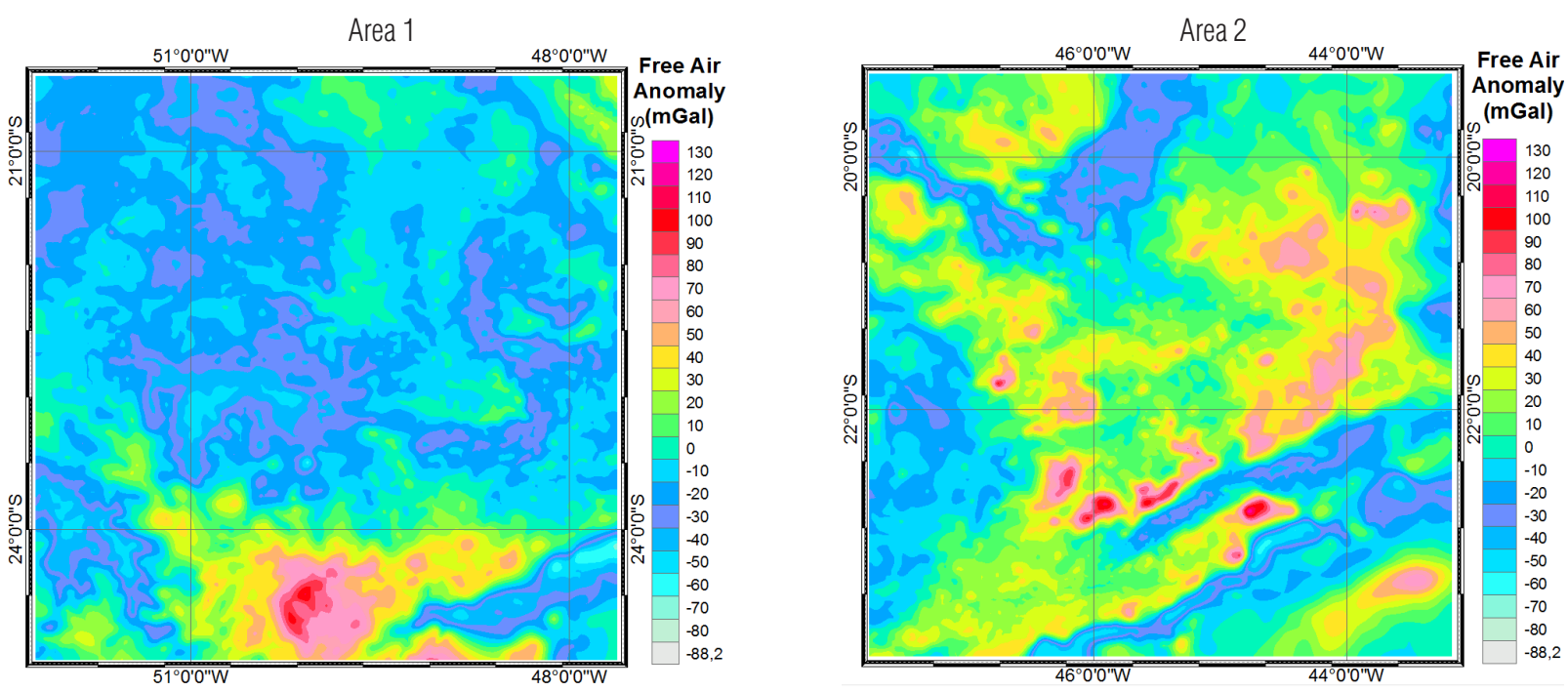

Figure 6 - Free air anomalies in mGal areas 1 and 2.
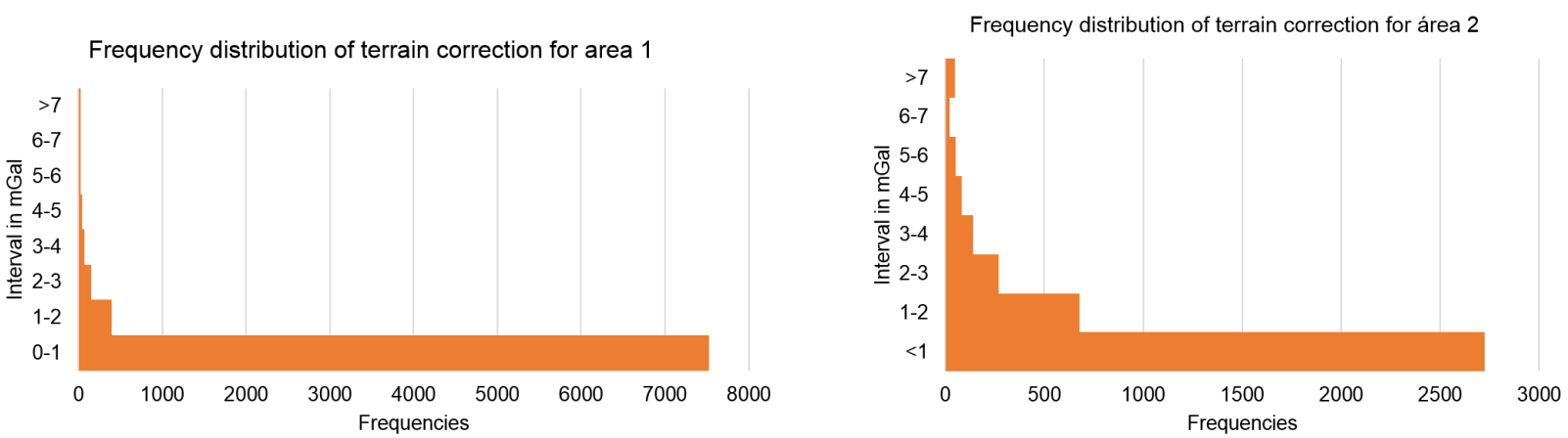

Figure 7 - Terrain correction for the areas 1 and 2.

tion of Bouguer. Besides that, in the reduction of Bouguer, there is a negative dislocation of the anomaly values, which denotes the great removal of masses.

The results in Table 4 indicate that the Bouguer method removes the masses causing significant alteration in the values of residual anomalies. However, Helmert and Rudzki methods have results closer to each other when compared to Bouguer. The reduction most commonly applied in the determination of the geoid is the Helmert's Second Condensation Method. This because it causes smaller variation of the potential after application.

To obtain the gravity anomaly values, $\Delta g_{M G G}$, it was used the set of coefficients of the EIGEN-6C4 geopotential model (European Improved Gravity model of the Earth by New techniques) up to the degree and order 200. This model was determined from information of gravimetric satellites GOCE, GRACE, LAGEOS and also from the data of the models DTU12 and EGM2008 being considered complete with degree and order up to 2190 (Förste et al., 2014). The adoption of this geopotential model is associated with the need to compare the results obtained here with those obtained by IBGE (2015) in the elaboration of MAPGEO 2015. According to IBGE (2015), the elaboration of MAPGEO 2015 also used the EIGEN-6C4 geopotential model up to the degree 200. In sequence, there are the results of the free air anomalies calculated by GeoFis 1.0 from the coefficients of the EIGEN6C4 for the study areas.

As observed in Figure 8, the results of the gravity anomaly obtained by GeoFis 1.0 for area 1 have higher concentration of values in the interval $-38-12 \mathrm{mGal}$. For area 1, the maximum concentration is between the values from -18 to $32 \mathrm{mGal}$.

With the definition of the anomalies of Faye, Bouguer and Rudzki and with the free air gravity anomalies of Global Geopotential Model (GGM), it can be determined the values of residual 

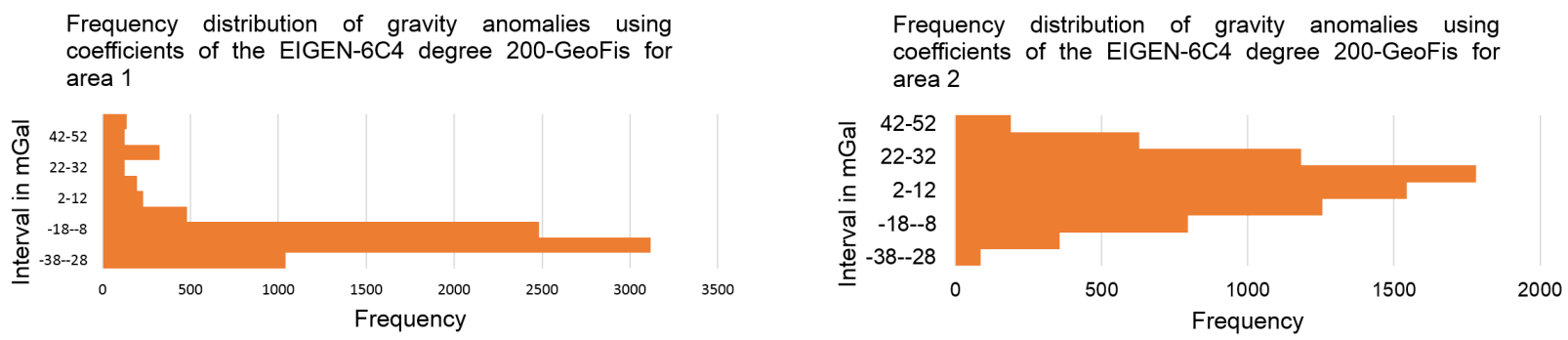

Figure 8 - Frequency distribution for the free air anomaly $\Delta g_{M G G}$ GeoFis.

anomalies for the study area using the different methods of reduction. The descriptive statistics of residual anomalies is presented in Tables 5 and 6.

Table $\mathbf{5}$ - Result of residual anomalies in mGal for area 1.

\begin{tabular}{|c|c|c|c|}
\hline Statistics & Helmert & Bouguer Rest & Rudzki \\
\hline Minimum & -83.636 & -83.971 & -79.076 \\
Maximum & 58.137 & 57.090 & 57.120 \\
Mean & 1.148 & 0.462 & 0.108 \\
Std Deviation & 13.848 & 13.757 & 12.244 \\
\hline
\end{tabular}

Table $\mathbf{6}$ - Result of residual anomalies in mGal for area 2.

\begin{tabular}{|c|c|c|c|}
\hline Statistics & Helmert & Bouguer Rest & Rudzki \\
\hline Minimum & -70.206 & -70.874 & -78.692 \\
Maximum & 125.976 & 115.416 & 97.858 \\
Mean & -5.890 & -6.653 & -5.147 \\
Std Deviation & 23.211 & 22.557 & 20.264 \\
\hline
\end{tabular}

The removal of long wavelengths resulted in considerable smoothing of residual anomalies for area 1. It is worth mentioning that for Bouguer, it was necessary to make the restoration and thus reduce the indirect effect caused by the removal of masses in the removal of the Bouguer plateau.

The results in Table 6 when compared to those in Table 4 evidence the smoothing in the values of anomalies when applying the removal of gravity anomalies of MGG.

The values of residual anomalies were interpolated to generate a regular grid. This process required to evaluate if the adopted interpolation did not generate gross errors that could compromise the integration process, both for the application of the integration process and convolution using the FFT.

According to Tziavos et al. (2005), the detection of gross errors in the utilization of a prediction process follows the following steps:

a) Divide the area in rectangular grids with compatible sizes with the mathematical model adopted; for each grid, it must be verified if the data are homogeneously distributed; b) Use the prediction method adopted having as input the "observed" values of residual anomaly and predict the values of anomalies in the observation points;

c) Estimate the module of difference between the original and the predicted values.

If the module of the difference between the observed and predicted values, $\left|\Delta g_{\text {obs }}-\Delta g_{\text {pred }}\right|$ is greater than the threshold,

$$
k \sqrt{\sigma^{2}\left(\Delta g_{o b s}-\Delta g_{p r e d}+\sigma^{2} \Delta g_{o b s}\right.},
$$

then, the observation in question is considered suspected of containing gross errors and can be eliminated. Where: $\Delta g_{o b s}$ is the residual anomaly value, $\Delta g_{\text {pred }}$ is the value of the predicted residual anomaly, $\sigma^{2}\left(\Delta g_{o b s}-\Delta g_{p r e d}\right)$ is the estimate of the mean square error of the difference between the observed and the predicted reduced anomaly, $\sigma^{2} \Delta g$ is the variance of observation $\Delta g_{o b s}$, and $k$ is a constant that varies from 2 to 5 depending on the rigor applied in the analysis.

This work followed the methodology proposed by Tziavos et al. (2005), by adopting for the set of observations the standard deviation of $\pm 5 \mathrm{mGal}$ and for $k$ the value of 2 .

The steps delineated above were implemented with geostatistics.

The module geostatistic analyst of the ArcGIS software allows to check for tendency in the data and also detect if the samples have spatial dependency. After confirming such dependency, the variable in study can be spatially modeled on the basis of the theory of regionalized variables, using the semivariogram as the main instrument. After generating the empirical semivariogram, it is possible to fit the theoretical model to the application of kriging, which is the process of prediction utilized in geostatistics.

Table 7 lists the statistical summary of applied prediction for each reduction method performed in area 1.

For area 2, the statistical summary of the prediction is presented in Table 8. 
Table 7 - Result of the prediction to generate the regular grid of residual anomalies using geostatistics for area 1 .

\begin{tabular}{|c|c|c|c|c|c|}
\hline Method & $\begin{array}{c}\text { EM } \\
\text { (mGal) }\end{array}$ & $\begin{array}{c}\text { RMS } \\
\text { (mGal) }\end{array}$ & $\begin{array}{c}\text { RMSS } \\
\text { (mGal) }\end{array}$ & "a" & $\begin{array}{c}\text { "b" } \\
\text { (mGal) }\end{array}$ \\
\hline Helmert & -0.049 & 6.257 & 0.679 & 0.742 & 0.285 \\
Bouguer & -0.049 & 6.210 & 0.674 & 0.742 & 0.113 \\
Rudzki & -0.023 & 4.305 & 0.669 & 0.830 & 0.025 \\
\hline
\end{tabular}

Table 8 - Result of the prediction to generate the regular grid of residual anomalies using geostatistics for area 2.

\begin{tabular}{|c|c|c|c|c|c|}
\hline Method & $\begin{array}{c}\text { EM } \\
\text { (mGal) }\end{array}$ & $\begin{array}{c}\text { RMS } \\
\text { (mGal) }\end{array}$ & $\begin{array}{c}\text { RMSS } \\
\text { (mGal) }\end{array}$ & "a" & $\begin{array}{c}\text { "b" } \\
\text { (mGal) }\end{array}$ \\
\hline Helmert & 0.140 & 7.647 & 1.316 & 0.925 & -0.163 \\
Bouguer & 0.130 & 5.950 & 1.264 & 0.941 & -0.129 \\
Rudzki & 0.122 & 6.010 & 1.185 & 0.928 & -0.232 \\
\hline
\end{tabular}

Regarding Tables 7 and 8, the values for RMS are smaller for residual anomalies of Rudzki for area 1 and residual anomalies of Bouguer for area 2. In relation to the Root Mean Square Standardized, RMSS, in area 1 it is overestimated the variability of prediction, once the RMSS value is lower than 1 . For area 2 , it is underestimated the variability of prediction, once the RMSS value was superior to 1. The coefficients "a" and "b" are also significant in the analysis. Values close to the unity for the coefficient "a" evidence a better fitted model and that occurred more clearly for area 2, where all values were superior to 0.9 . For the coefficient "b", values close to zero are expected. Based on this information, it is verified whether the prediction model is well adjusted and can be considered a good estimator.

The prediction methods determined the absolute error between the predicted value and the observed value and also its variance. With these values, it is possible to detect values suspected of containing gross errors as shown in Eq. (13). Thus, from the total of 8257 observations of area 1, 395 samples were considered suspected of containing gross errors and for area 2, from the total of 8049 observations, 346 were samples considered suspected of containing gross errors.

$$
>k \sqrt{\sigma^{2}\left(\Delta g_{o b s}-\Delta g_{\text {pred }}\right)+\sigma^{2} \Delta g_{\text {obs }}}
$$

The next step for determining the gravimetric undulation of the geoid consists in calculating the value of the residual geoid undulation, $N_{\text {res }}$. This phase employed the integration, the planar FFT and the 1D-FFT.

The descriptive statistics in Table 9 presents the results for the calculation of the residual undulation, $N_{\text {res }}$, using Geo-
Fis 1.0, by the integration process, and using the software FFTGEOID for the planar FFT and the 1D-FFT for area 1.

In the comparative analysis between the obtained values via integration with those obtained by FFT, Table 9, on average, the Helmert's Second Condensation Method presented higher mean of $N_{\text {res }}$ than Bouguer and Rudzki. Analyzing the values of the mean $N_{\text {res }}$ for Bouguer and Rudzki after the application of the integration and FFT, it is verified a good consistency between the values.

Comparing the obtained results for the residual undulation in area 2, Table 10, it is verified that in absolute terms, the mean values of $N_{\text {res }}$ obtained by FFT were superior to the mean values obtained in the integration for the three methods of reduction. When related to each other, the mean values obtained by the planar FFT and 1D-FFT, for all reductions, were more consistent with the maximum absolute difference of $0.031 \mathrm{~m}$ for the $N_{\text {res }}$ of Bouguer.

At the end of the removal step, the restore step starts. This step begins with the calculation of the geoid undulation values from the coefficients of the geopotential model adopted, in this case, the EIGEN-6C4. The summarized results are listed in Table 11.

Still in the restore step, it is necessary to consider the distortion in the potential that occurs due to the removal of masses and calculate the indirect effect. This effect is used to, from the cogeoid, surface obtained at the end of the gravimetric reductions, calculate the geoid. This effect is determined by the application of the equation of Bruns to the variation of the spheropotential (Martinec \& Vaníček, 1994):

$$
N_{E I}=\partial W / \gamma .
$$

The indirect effect, for the reference points, was obtained using the GeoFis 1.0. The statistical summary for this effect is listed in Table 12.

As it can be observed in Table 12, the obtained values for the indirect effect are all negative. In absolute terms, the values of greater amplitude of the indirect effect are 0.026 meters for area 1 and 0.051 meters for area 2. Since this effect is due to the alteration in the potential generated by the displacement of topographic masses, then, the results show that there is larger impact of these masses in the determination of the geoid model for area 2 than for area 1.

The restore step determines the geoid undulation by adding the components calculated in the previous steps. The summaries of the results of such addition are presented in Table 13 for area 1 and in Table 14 for area 2. 
Table 9 - Statistical summary of the residual undulation calculated for area 1.

\begin{tabular}{|c|c|c|c|c|c|c|c|c|c|}
\hline \multirow{3}{*}{ Statistics } & \multicolumn{3}{|c|}{$N_{\text {res }}(\mathrm{m})$} & \multicolumn{3}{c|}{$N_{\text {res }}(\mathrm{m})$} & \multicolumn{3}{c|}{$N_{\text {res }}(\mathrm{m})$} \\
\cline { 2 - 10 } & Integration using the GeoFis 1.0 & \multicolumn{2}{c|}{ FFT planar by the FFTGE0ID } & \multicolumn{3}{c|}{ FFT-1D by the FFTGE0ID } \\
\cline { 2 - 9 } & Helmert & Bouguer & Rudzki & Helmert & Bouguer & Rudzki & Helmert & Bouguer & Rudzki \\
\hline Minimum & -0.128 & -0.186 & -0.191 & -0.061 & -0.138 & -0.157 & -0.036 & -0.118 & -0.152 \\
Maximum & 0.377 & 0.315 & 0.258 & 0.469 & 0.386 & 0.300 & 0.483 & 0.396 & 0.312 \\
Mean & 0.119 & 0.057 & 0.035 & 0.155 & 0.072 & 0.036 & 0.161 & 0.073 & 0.035 \\
Std Deviation & 0.155 & 0.153 & 0.141 & 0.163 & 0.160 & 0.142 & 0.161 & 0.159 & 0.141 \\
\hline
\end{tabular}

Table 10 - Statistical summary of the residual undulation calculated for area 2.

\begin{tabular}{|c|c|c|c|c|c|c|c|c|c|}
\hline \multirow{3}{*}{ Statistics } & \multicolumn{3}{|c|}{$N_{\text {res }}(\mathrm{m})$} & \multicolumn{3}{c|}{$N_{\text {res }}(\mathrm{m})$} & \multicolumn{3}{c|}{$N_{\text {res }}(\mathrm{m})$} \\
\cline { 2 - 9 } & Integration using the GeoFis 1.0 & \multicolumn{3}{c|}{ Planar FFT by FFTGEOID } & \multicolumn{3}{c|}{ 1D-FFT by FFTGEOID } \\
\cline { 2 - 9 } & Helmert & Bouguer & Rudzki & Helmert & Bouguer & Rudzki & Helmert & Bouguer & Rudzki \\
\hline Minimum & -0.923 & -1.007 & -0.774 & -1.185 & -1.298 & -1.008 & -1.224 & -1.344 & -1.039 \\
Maximum & 0.277 & 0.185 & 0.282 & 0.151 & 0.035 & 0.174 & 0.135 & 0.012 & 0.162 \\
Mean & -0.217 & -0.308 & -0.181 & -0.329 & -0.450 & -0.266 & -0.353 & -0.481 & -0.284 \\
Std Deviation & 0.322 & 0.321 & 0.290 & 0.355 & 0.356 & 0.324 & 0.362 & 0.363 & 0.330 \\
\hline
\end{tabular}

Table 11 - Statistical summary of the values of $N_{M G G}$ calculated using the MGG EIGEN-6C4.

\begin{tabular}{|c|c|c|}
\hline Statistics & Area 1 & Area 2 \\
& $N_{M G G}(\mathrm{~m})$ & $N_{M G G}(\mathrm{~m})$ \\
\hline Minimum & -6.244 & -4.858 \\
Maximum & -4.658 & -2.438 \\
Mean & -5.530 & -3.841 \\
Std Deviation & 0.532 & 0.593 \\
\hline
\end{tabular}

Table 12 - Statistical summary of the calculated results for the indirect effect for the study areas.

\begin{tabular}{|c|c|c|}
\hline Statistics & Area 1 & Area 2 \\
& $N_{E I}(\mathrm{~m})$ & $N_{E I}(\mathrm{~m})$ \\
\hline Minimum & -0.026 & -0.051 \\
Maximum & -0.009 & -0.037 \\
Mean & -0.017 & -0.042 \\
Std Deviation & 0.005 & 0.004 \\
\hline
\end{tabular}

Table 13 - Descriptive statistics of the gravimetric geoid undulation for the three methods of gravimetric reduction proposed for area 1.

\begin{tabular}{|c|c|c|c|c|c|c|c|c|c|}
\hline \multirow{2}{*}{ Statistics } & \multicolumn{3}{|c|}{$\mathrm{N}$ (meters) - using integration } & \multicolumn{3}{c|}{$\mathrm{N}$ (meters) - using planar FFT } & \multicolumn{3}{c|}{$\mathrm{N}$ (meters) - using 1D-FFT } \\
\cline { 2 - 10 } & Helmert & Bouguer & Rudzki & Helmert & Bouguer & Rudzki & Helmert & Bouguer & Rudzki \\
\hline Minimum & -6.018 & -6.070 & -6.099 & -6.045 & -6.118 & -6.144 & -6.036 & -6.114 & -6.139 \\
Maximum & -4.424 & -4.470 & -4.490 & -4.310 & -4.381 & -4.428 & -4.323 & -4.398 & -4.453 \\
Mean & -5.428 & -5.473 & -5.495 & -5.392 & -5.458 & -5.494 & -5.386 & -5.457 & -5.495 \\
Std Deviation & 0.530 & 0.527 & 0.537 & 0.5490 & 0.545 & 0.550 & 0.538 & 0.534 & 0.540 \\
\hline
\end{tabular}


Table 14 - Descriptive statistics of the gravimetric geoid undulation for the three methods of gravimetric reduction proposed for area 2.

\begin{tabular}{|c|c|c|c|c|c|c|c|c|c|}
\hline \multirow{2}{*}{ Statistics } & \multicolumn{3}{|c|}{$\mathrm{N}$ (meters) - using integration } & \multicolumn{2}{c|}{$\mathrm{N}$ (meters) - using planar FFT } & \multicolumn{2}{c|}{$\mathrm{N}$ (meters) - using 1D-FFT } \\
\cline { 2 - 10 } & Helmert & Bouguer & Rudzki & Helmert & Bouguer & Rudzki & Helmert & Bouguer & Rudzki \\
\hline Minimum & -4.728 & -4.780 & -4.694 & -4.834 & -4.918 & -4.769 & -4.844 & -4.937 & -4.777 \\
Maximum & -3.399 & -3.445 & -3.212 & -3.661 & -3.736 & -3.446 & -3.700 & -3.782 & -3.477 \\
Mean & -4.100 & -4.149 & -4.022 & -4.212 & -4.291 & -4.107 & -4.236 & -4.322 & -4.125 \\
Std Deviation & 0,366 & 0,369 & 0,422 & 0.360 & 0.364 & 0.413 & 0.354 & 0.358 & 0.410 \\
\hline
\end{tabular}

Analyzing the obtained values for the three methods of reduction and by the application of the three techniques: integration, planar FFT and 1D-FFT, it is verified that, in absolute terms, the larger difference between the $\mathrm{N}$ gravimetric calculated mean occurred for the Helmert's Second Condensation Method between the integration and the 1D-FFT, namely 0.042 meters. As there is good adhesion between the values of Nres calculated for area 1 .

In the analysis of the results in Table 14, the largest absolute difference between the mean values of the gravimetric geoid occurred for the reduction of Bouguer between the process of integration and the 1D-FFT, $0.173 \mathrm{~m}$. The smaller absolute difference between the mean values of the gravimetric geoid was found for the reduction of Rudzki between the processes of integration and the planar FFT, 0.085 meters.

To analyze the results obtained by the RR technique, gravimetric geoid, two references were established, GNSS/leveling and the MAPGEO 2015 model. Table 15 presents the absolute residuals between the gravimetric geoid obtained via RR and the geoid undulation of the GNSS/leveling reference. The same Table lists the statistical summary of the difference between the gravimetric geoid undulation and the MAPGEO 2015 for area 1.

In the results in Table 15, for the difference between the gravimetric geoid and the geometric geoid, it is verified the highest mean of 0.136 meters for the reduction of Rudzki. In the case of the residual between the gravimetric geoid and the MAPGEO 2015, the highest mean was 0.096 meters for the reduction of Bouguer.

Table 16 presents the absolute residuals between the gravimetric geoid, applying the planar FFT, and the undulation of reference GNSS/leveling. Still in Table 16, for the planar FFT, it is presented the statistical summary of the difference between the gravimetric geoid undulation and the MAPGEO 2015 for area 1.

It can be concluded that, considering the data in Table 17, that the planar FFT applied to the gravimetric data of area 1 resulted in higher mean residual, 0.166 meters for the difference between the gravimetric geoid and the geometric geoid, and 0.190 meters for the difference between the gravimetric geoid and the
MAPGE0, both for Rudzki Method.

Table 17 presents the absolute residuals between the undulation obtained via RR, applying the 1D-FFT and the geoid undulation of reference GNSS/leveling. It is also verified in Table 17, for the 1D-FFT, the statistical summary of the difference between the gravimetric geoid undulation and the MAPGEO 2015.

By analyzing Table 17, it is verified that the highest mean residual between the gravimetric and the geometric geoid was 0.170 meters and for the difference between the gravimetric geoid and the MAPGE0, the largest residual was 0.191 meters, both for Rudzki Method.

For area 2, the absolute residuals between the gravimetric undulation obtained via RR and the geometric geoid, applying the integration, are presented in Table 18. This table also shows the statistical summary of the difference between the gravimetric geoid undulation and the MAPGEO 2015.

The greatest residual for the difference between the gravimetric geoid and the geometric geoid was found for the reduction of Bouguer, with 0.049 meters, according to Table 18. In this same table, it is verified that the largest residual between the gravimetric geoid and the MAPGEO is 0.295 meters.

The absolute residuals between the geoid undulation, obtained via RR applying the planar FFT, and the GNSS/leveling for area 2 are presented in Table 19. This table presents the statistical summary of the difference between the gravimetric geoid undulation and the MAPGEO 2015.

Analyzing the data in Table 19, the highest mean residual between the gravimetric geoid and the geometric geoid occurred for Bouguer, 0.630 meters. However, in the comparison between the gravimetric geoid and the MAPGEO, the greater mean residual was 0.437 meters also for the reduction of Bouguer.

Table 20 shows the absolute residuals between the undulation obtained via RR applying the 1D-FFT and the GNSS/leveling. Still, Table 20 presents the statistical summary of the absolute difference between the undulation of the gravimetric geoid and the MAPGE0 2015 for area 2.

In the analysis of Table 20 , it is verified maximum residuals 
Table 15 - Descriptive statistics of the residual for the gravimetric geoid obtained by the RR from the integration for area 1.

\begin{tabular}{|c|c|c|c|c|c|c|}
\hline \multirow{3}{*}{ Statistics } & \multicolumn{3}{|c|}{ Residual (meters) } & \multicolumn{3}{c|}{ Residual (meters) } \\
\cline { 2 - 7 } & \multicolumn{2}{|c|}{ Gravimetric geoid - geometric } & \multicolumn{3}{c|}{ Gravimetric geoid - MAPGE0 2015 } \\
\cline { 2 - 7 } & Helmert & Bouguer & Rudzki & Helmert & Bouguer & Rudzki \\
\hline Minimum & 0.001 & 0.003 & 0.002 & 0.001 & 0.005 & 0.031 \\
Maximum & 0.395 & 0.446 & 0.470 & 0.281 & 0.324 & 0.329 \\
Mean & 0.134 & 0.149 & 0.162 & 0.131 & 0.170 & 0.192 \\
Std Deviation & 0.123 & 0.133 & 0.136 & 0.086 & 0.096 & 0.083 \\
\hline
\end{tabular}

Table 16 - Descriptive statistics of the residual for the gravimetric geoid obtained via RR by the application of the planar FFT for area 1.

\begin{tabular}{|c|c|c|c|c|c|c|}
\hline \multirow{3}{*}{ Statistics } & \multicolumn{3}{|c|}{ Residual (meters) } & \multicolumn{3}{c|}{ Residual (meters) } \\
\cline { 2 - 7 } & Gravimetric geoid - geometric & \multicolumn{3}{c|}{ Gravimetric geoid - MAPGE0 2015 } \\
\cline { 2 - 7 } & Helmert & Bouguer & Rudzki & Helmert & Bouguer & Rudzki \\
\hline Minimum & 0.001 & 0.010 & 0.009 & 0.006 & 0.012 & 0.054 \\
Maximum & 0.415 & 0.466 & 0.504 & 0.214 & 0.273 & 0.292 \\
Mean & 0.128 & 0.145 & 0.166 & 0.107 & 0.159 & 0.190 \\
Std Deviation & 0.115 & 0.123 & 0.130 & 0.063 & 0.081 & 0.069 \\
\hline
\end{tabular}

Table 17 - Descriptive statistics of the residual for the gravimetric geoid obtained via RR by the application of the 1D-FFT for area 1.

\begin{tabular}{|c|c|c|c|c|c|c|}
\hline \multirow{3}{*}{ Statistics } & \multicolumn{3}{|c|}{ Residual (meters) } & \multicolumn{3}{c|}{ Residual (meters) } \\
\cline { 2 - 7 } & \multicolumn{2}{|c|}{ Gravimetric geoid - geometric } & \multicolumn{3}{c|}{ Gravimetric geoid - MAPGE0 2015 } \\
\cline { 2 - 7 } & Helmert & Bouguer & Rudzki & Helmert & Bouguer & Rudzki \\
\hline Minimum & 0.000 & 0.014 & 0.016 & 0.001 & 0.026 & 0.030 \\
Maximum & 0.421 & 0.470 & 0.513 & 0.197 & 0.263 & 0.284 \\
Mean & 0.130 & 0.150 & 0.170 & 0.106 & 0.160 & 0.191 \\
Std Deviation & 0.120 & 0.124 & 0.131 & 0.059 & 0.079 & 0.074 \\
\hline
\end{tabular}

Table 18 - Descriptive statistics of the residual for the gravimetric geoid obtained via RR by the integration for area 2.

\begin{tabular}{|c|c|c|c|c|c|c|}
\hline \multirow{3}{*}{ Statistics } & \multicolumn{3}{|c|}{ Residual (meters) } & \multicolumn{3}{c|}{ Residual (meters) } \\
\cline { 2 - 7 } & \multicolumn{2}{|c|}{ Gravimetric geoid - geometric } & \multicolumn{3}{c|}{ Gravimetric geoid - MAPGE0 2015 } \\
\cline { 2 - 7 } & Helmert & Bouguer & Rudzki & Helmert & Bouguer & Rudzki \\
\hline Minimum & 0.125 & 0.079 & 0.147 & 0.048 & 0.100 & 0.014 \\
Maximum & 0.883 & 0.933 & 0.824 & 0.487 & 0.528 & 0.292 \\
Mean & 0.449 & 0.494 & 0.375 & 0.247 & 0.295 & 0.169 \\
Std Deviation & 0.180 & 0.184 & 0.141 & 0.123 & 0.120 & 0.072 \\
\hline
\end{tabular}

of 0.662 meters between the gravimetric geoid and the geometric geoid and 0.469 meters between the gravimetric geoid and the MAPGEO, in both cases, for the reduction of Bouguer.

\section{CONCLUSIONS}

At the end of the applications, for area 1, the largest mean residual obtained between the gravimetric geoid and the geometric geoid was given by the application of the 1D-FFT for the reduction of Rudzki. For the mean residual, between the gravimetric geoid and the MAPGEO, the highest value was found with the application of 1D-FFT, also for Rudzki reduction. It is important to highlight that the smaller mean residual values, for the difference between the gravimetric geoid and the geometric geoid, were obtained for the Helmert's Second Condensation Method with the application of planar FFT. In turn, the lower mean residual difference between the gravimetric geoid and the MAPGEO 2015 was obtained by the application of the 1D-FFT for the Helmert's Second Condensation Method. 
Table 19 - Descriptive statistics of the residual for the gravimetric geoid obtained via RR by the application of the planar FFT for area 2.

\begin{tabular}{|c|c|c|c|c|c|c|}
\hline \multirow{3}{*}{ Statistics } & \multicolumn{3}{|c|}{ Residual (meters) } & \multicolumn{3}{c|}{ Residual (meters) } \\
\cline { 2 - 7 } & Gravimetric geoid - geometric & \multicolumn{3}{c|}{ Gravimetric geoid - MAPGE0 2015 } \\
\cline { 2 - 7 } & Helmert & Bouguer & Rudzki & Helmert & Bouguer & Rudzki \\
\hline Minimum & 0.035 & 0.036 & 0.134 & 0.154 & 0.238 & 0.089 \\
Maximum & 0.888 & 0.967 & 0.792 & 0.681 & 0.756 & 0.466 \\
Mean & 0.554 & 0.630 & 0.455 & 0.359 & 0.437 & 0.253 \\
Std Deviation & 0.189 & 0.196 & 0.139 & 0.140 & 0.139 & 0.092 \\
\hline
\end{tabular}

Table 20 - Descriptive statistics of the difference between the undulation of the geoid using RR, 1D-FFT, and the geometric geoid for area 2.

\begin{tabular}{|c|c|c|c|c|c|c|}
\hline \multirow{3}{*}{ Statistics } & \multicolumn{3}{|c|}{ Residual (meters) } & \multicolumn{3}{c|}{ Residual (meters) } \\
\cline { 2 - 7 } & \multicolumn{2}{|c|}{ Gravimetric geoid - geometric } & \multicolumn{3}{c|}{ Gravimetric geoid - MAPGE0 2015 } \\
\cline { 2 - 7 } & Helmert & Bouguer & Rudzki & Helmert & Bouguer & Rudzki \\
\hline Minimum & 0.014 & 0.064 & 0.119 & 0.164 & 0.257 & 0.097 \\
Maximum & 0.918 & 1,004 & 0.806 & 0.720 & 0.802 & 0.497 \\
Mean & 0.576 & 0.662 & 0.473 & 0.382 & 0.469 & 0.271 \\
Std Deviation & 0.198 & 0.200 & 0.143 & 0.148 & 0.147 & 0.097 \\
\hline
\end{tabular}

For area 2, the greater residuals observed for the difference between the gravimetric geoid and the geometric geoid and between the gravimetric geoid and the MAPGEO occurred for the reduction of Bouguer with the application of the 1D-FFT. Still for area 2, the smallest mean residual verified between the gravimetric geoid and the geometric geoid occurred for the integration applying the reduction of Rudzki. This also occurred for the smallest mean residual between the gravimetric geoid and the MAPGEO

In the analyses conducted, for all applications, the gravimetric geoid for area 1 presents smaler mean residuals than the gravimetric geoid obtained for area 2. In this case, a further detailed analysis, such as the use of more accurate MDTs and the application of different density values, can improve even more the model.

Finally, it is verified that the physical characteristics, geology and relief of the study areas are relevant in determining the geoid and which specific procedures have to be considered in the modeling.

\section{REFERENCES}

BAJRACHARYA S. 2003. Terrain effects on geoid determination. MSC Dissertation, rep 20181, Department of Geomatics Engineering, University of Calgary, Alberta, Canada. 114 pp.

FÖRSTE C, BRUINSMA SL, ABRIKOSOV O, LEMOINE J-M, MARTY JC, FLECHTNER F, BALMINO G, BARTHELMES F \& BIANCALE R. 2014. EIGEN-6C4 The latest combined global gravity field model including GOCE data up to degree and order 2190 of GFZ Potsdam and GRGS
Toulouse. GFZ Data Services. http://doi.org/10.5880/icgem.2015.1.

GEMAEL C. 1999. Introdução à GeodésiaFísica. Editora da Universidade Federal do Paraná, Curitiba, Brazil, 304 pp.

GEMAEL C \& ROSIER F. 1991. Calibração de gravímetros usando a RENEGA. In: Congresso Internacional da Sociedade Brasileira de Geofísica. 2., Salvador, Brazil. Anais, pp. 120-124.

HOFMANN-WELLENHOF B \& MORITZ H. 2005. Physical Geodesy. Springer, Wien-NewYork. $410 \mathrm{pp}$.

IBGE - INSTITUTO BRASILEIRO DE GEOGRAFIA E ESTATÍSTICA. 2015. 0 novo modelo de ondulação geoidal do Brasil MAPGE02015. Avaiable on: < ftp://geoftp.ibge.gov.br/modelos_digitais_de_superficie/ modelo_de_ondulacao_geoidal/cartograma/rel_mapge02015.pdf > . Access on: April 2015.

JEKELI C. 2006. Geometric Reference Systems. Division of Geodesy and Geoespacial Science. School of Earth Sciences. The Ohio State University. $195 \mathrm{pp}$.

KIAMEHR R \& SJÖBERG LE. 2005. Effect of the SRTM global DEM on the determination of a high-resolution geoid model: a case study in Iran. Journal of Geodesy, 79: 540-551.

LEICK A. 1995. GPS Satellite Surveying. 2nd ed., New York: John Wiley \& Sons, $560 \mathrm{pp}$.

LISTING JB. 1873. Uber unsere jetzige Kenntnis der Gestalt und Grosse der Erde, Nachr. d. Kgl., Gesellsch. d. Wiss. und der Georg-AugustUniv., 33-98, Gottingen.

MAXQ \& WATTS DR. 1994. Terrain correction program for regional gravit 
surveys. Computers \& Geosciences, 20(6): 961-972. Elsevier Science Ltd., Liverpool.

MARQUES ET, DAL POZ WR, FREITAS JS \& GUIMARÃES GN. 2017. Desenvolvimento de um Software para Cálculo da Ondulação Geoidal usando a Técnica Remover Restaurar. Revista Brasileira de Cartografia, No prelo.

MARTINEC Z \& VANÍČEK P. 1994. Indirect effect of topography in the Stokes-Helmert technique for a spherical approximation of the geoid. Manuscripta Geodaetica, 19: 257-268.

SEVILLA MJ, RAMÍREZ HUERTA D \& SÁNCHEZ MENÉNDEZ FJ. 1997. Metodología para la creación de bases de datos gravimétricos fiables: Métodos clásicos, gráficos y digitales (I). Revista Topografía y Cartografía, ISSN: 0212-9280, 14(79): 2-19.

SIDERIS MG. 1997. Geoid Determination by FFT Technique. In: Lecture Notes of IAG's Geoid School, Rio de Janeiro, Brazil.

SIDERIS MG \& LI Y. 1993. Gravity field convolutions without windowing and edge effects. Bulletin Géodésique, 67(2): 107-118.

SOUZA SF, MATSUOKA MT, GÖTZ JJ \& SEVERO TC. 2008. Sobre 0 novo modelo do geopotencial EGM2008. In: SOUZA SF \& MATSUOKA MT (Org.). Série em Geomática: 10 anos do Curso de Engenharia Cartográfica da UFRGS. 2nd ed., Porto Alegre, Brazil. Instituto de
Geociências, 2: 67-73.

STOKES GG. 1849. On the variation of gravity at the surface of the Earth. Transactions of the Cambridge Philosophical Society, 8: 672.

TALVIK S. 2012. Influence of the gravitational attraction of terraced landforms to precise levelling results. In: The Council of European Geodetic Surveyors, Comité de Liasion des Géomètres Européens. BrusselsBelgium.

TZIAVOS I, VERGOS G \& ANDRITSANOS V. 2005. Gravity Data Base Generation and Geoid Model Estimation using Heterogeneous Data. In: JEKELI C, BASTOS L \& FERNANDES J (Eds.). Gravity, Geoid and Space Missions. International Association of Geodesy Symposia, vol. 129. Springer, Berlin, Heidelberg.

WICHIENCHAROEN C. 1982. The indirect effects on the computation of geoids undulations. OSU Reports 336, Department of Geodetic Science and Surveying, The Ohio State University, Ohio, USA. 96 pp.

YILDIZ H, FORSBERG R, ÅGREN J, TSCHERNING CC \& SJÖBERG LE. 2012. Comparison of remove-compute-restore and least squares modification of Stokes' formula techniques to quasi-geoid determination over the Auvergne test area. Journal of Geodetic Science, 2(1): 53-64, doi: 10.2478/v10156-011-0024-9. 